\section{AS VIOLÊNCIAS SOFRIDAS POR MULHERES QUE OFENDERAM SEXUALMENTE}

\author{
VIOLENCES SUFFERED BY WOMEN WHO OFFENDED SEXUALLY
}

RESUMO: 0 objetivo deste texto é apresentar e discutir histórias das várias vitimizações sofridas pela ofensora sexual do gênero feminino, buscando contribuir para os atendimentos psicossociais. Trata-se de um recorte de pesquisa desenvolvida em parceria entre uma instituição pública e uma universidade pública, e a opção metodológica foi a pesquisa documental, com a obtenção das informações retiradas diretamente do registro contido nos prontuários da instituição. As participantes foram cinco mulheres com idades entre 19 e 52 anos que receberam atendimento psicossocial após encaminhamento de serviços de justiça e saúde, durante o primeiro semestre de 2018. 0s resultados apontam histórias de intenso sofrimento vividas por essas mulheres que tiveram início muito precocemente na infância, sendo contínuas, permanentes, com várias facetas: física, abandono, negligência, vivência de rua, violência sexual. Ainda ocorreram mortes, separações e ruptura de vínculos afetivos, grandes mudanças e desvinculações do ambiente. A vivência dessas várias violências trouxe consequências graves para o desenvolvimento da afetividade e estabelecimento e manutenção de relações vinculares. Esses resultados são coincidentes com a literatura internacional. 0 aspecto analisado nesse texto necessita ser considerado em qualquer programa de intervenção psicossocial ou clínico com essas mulheres.

PALAVRAS-CHAVE: Mulher ofensora sexual; Abuso sexual; Violência; Vitimização.
ABSTRACT: The purpose of the text is to present and discuss history of the various victimizations suffered by the female sex offender in order to contribute to psychosocial care. It is a research cut developed in partnership between a public institution and a public university, and the methodological option was the documentary research, with the obtaining of information taken directly from the record contained in the institution's health records. The participants were five women between the ages of 19 and 52 who received psychosocial care after referral of justice and health services during the first half of 2018. The results point to stories of intense suffering experienced by these women who started very early in childhood, being continuous, permanent, with many facets: physical, neglect, street life and sexual violence. There were still deaths, separations, rupture of affective bonds, great changes and disengagement of the environment and of people. The experience of these various violence has had grave consequences on the development of affectivity and the establishment and maintenance of binding relationships. These results coincide with the international literature. The aspect analyzed in this text needs to be included in any program of psychosocial or clinical intervention with these women.

KEYWORDS: Sexual offender female; Sexual abuse; Violence; Victimization.

\title{
ARTIGO
}

CASSIA DE FREITAS TEIXEIRA PASSARELA ${ }^{1}$

\section{LUCY MARY \\ CAVALCANTI STROHER}

\section{LIANA FORTUNATO COSTA $^{2}$}

${ }^{1}$ Secretaria de Estado de Saúde do Distrito Federal (DF), Brasilia, Brasil

2 Universidade de Brasilia, Brasilia (DF), Brasil
Este texto tem por objetivo apresentar e discutir as histórias das várias vitimizações sofridas pela ofensora sexual do gênero feminino, conforme é relatado amplamente pela literatura internacional (Cauffman, 2008; Comartin, BurgessProctor, Kubiak \& Kernsmith, 2018; Grattagliano, Owens, Morton, Campobasso, Carabelle, \& Catanesi, 2012; Levenson, Willis, \& Prescott, 2015; Strickland, 2008; Willis \& Levenson, 2016). Os casos de violência sexual cometidos por mulheres
Recebido em: 09/01/2019 Aprovado em: 25/04/2019 
tiveram identificação, em países de língua inglesa, a partir das décadas de 1980/1990 (Pflugradt, Allen, \& Marshall, 2018). Ainda hoje muitos casos se mantêm desconhecidos e inacessíveis, e há uma tendência a serem menosprezados por conta do mito sobre a mulher, vista sempre como cuidadora (Strickland, 2008). Essa desqualificação da violência cometida por mulheres contra crianças e adolescentes é particularmente observada no contexto jurídico que se mostra leniente e, muitas vezes, irresponsável em relação a identificar e responsabilizar a mulher ofensora sexual (Cauffman, 2008; Kington, 2014). Por outro lado, há uma tendência a se categorizar a mulher ofensora sexual como portadora de problemas mentais, ou então como pessoa má, evidenciando com esta leitura patologizante ou moralista uma dificuldade geral (até mesmo de profissionais da psicologia e juristas) de reconhecer sua condição de sofrimento. Em outros termos, de se aproximar da subjetividade das mulheres em questão e, até, de realizarem o encaminhamento para atendimento específico (Cauffman, 2008; Nicoletti, Giacomozzi, \& Cabral, 2017; Peter, 2006).

A indicação correta de prevalência do abuso sexual cometido por mulheres é desconhecida. Alguns estudos apontam uma prevalência de $4 \%$ a $6 \%$ de ocorrência de abuso sexual cometido por mulheres em comparação com o cometimento de abusos sexuais de forma geral. Porém, essa estimativa pode ser maior se a contagem for realizada a partir do relato de adultos que foram vítimas sexuais de mulheres na infância (Cortoni, Babchishin, \& Rat, 2017).

O conhecimento sobre o cometimento da violência sexual por mu- lher adulta ou adolescente, em nosso país, é praticamente nulo. No Distrito Federal (Brasil), no ano de 2018, haviam cinco mulheres adultas sentenciadas por abuso sexual e recolhidas ao sistema prisional (Ronny Alves de Jesus, comunicação pessoal, em 15 de outubro de 2018). E é muito recente o despertar do interesse do Ministério Público por encaminhamento para atendimento clínico dessas mulheres (Thiago André Pierobom de Ávila, comunicação pessoal, em 15 de outubro de 2018). Dessa forma, constata-se que começa a surgir uma demanda institucional mais sistematizada por identificar mulheres que cometeram ofensa sexual e se estabelecer oferecimento de ações de atendimento psicológico a essa população. Exemplo disto é que o Ministério da Saúde (2015), na ficha de notificação de violência interpessoal/autoprovocada, trouxe espaço para preenchimento de variável sobre o tipo de violência sexual praticada, o sexo e a faixa etária do autor da violência, no intuito de mapear e trazer ao conhecimento público essa prevalência. Espera-se, em futuro próximo, haver conhecimento mais detalhado desse fenômeno, no entanto, agora o índice de mulheres autoras de violência sexual é quase inexistente.

Este texto pretende contribuir não apenas para visibilizar estas mulheres que ofenderam sexualmente, porém, mais especificamente contribuir para a iniciativa de encaminhamentos para atendimentos na rede (pública e privada). Além disso, apresenta as histórias de violências sofridas e vitimizações pelas mulheres adultas ofensoras sexuais em concordância com a unanimidade dos autores internacionais que privilegiam o conhecimento desse aspecto no tratamento desses sujeitos (Blom, Högberg, Olofsson, \& Danielsson, 2014; Kington, 2014; Levenson 
et al., 2015; Willis \& Levenson, 2016; Gillespie, Williams, Elliot, \& Eldridge, 2017). Sem exceção, os autores citados neste texto concordam que a mulher que comete ofensa sexual sofreu graves injúrias na infância e na pré-adolescência, como violência sexual vivida de forma severa, além de outras violências, trazendo experiência traumática e grande sofrimento para sua história de vida. Assim, tem-se que a criação de políticas públicas e de ações terapêuticas depende enormemente do conhecimento que se produza sobre um aspecto fundamental para a criação de métodos de atendimento, qual seja: a vitimização precoce da ofensora sexual, do ponto de vista físico, emocional, sexual, social e familiar (Willis \& Levenson, 2016).

Os estudos sobre a mulher ofensora sexual mostram que elas foram vítimas de maus-tratos, e de que sua história de violências sofridas é maior do que as histórias dos maus-tratos sofridos pelos homens ofensores sexuais. Além disto, estas mulheres foram expostas a modos de relacionamento agressivo e abusivo. As violências e maus-tratos são de ordem física, emocional e principalmente sexual. Essas violências sexuais foram, em geral, cometidas por familiares, e, sobre elas, tem-se ainda a dizer que essas mulheres sofreram um processo permanente de erotização (Budd \& Bierie, 2018; Burger-Proctor, Comartin, \& Kubiak, 2017; Oliver \& Holmes, 2015).

Há evidências em pesquisas que mostram que as mulheres que cometeram ofensa sexual sofreram abuso sexual por um número maior de abusadores, sendo que a primeira vitimização ocorreu em idade precoce, tendo permanecido subjugadas à violência por longo tempo. De forma geral, as mulheres que cometeram algum tipo de crime sofreram várias e múltiplas vitimizações na infância. Porém, a mulher vitimizadora sexual sofreu maior número de violências do que as mulheres ofensoras não sexuais. Esses achados têm relação intensa com preconceitos de gênero, apontando uma posição social da mulher como submissa, dominada e violentada (Lauritsen \& CarboneLopez, 2011; Williams et al., 2017; Willis \& Levenson, 2016).

De modo semelhante, os homens adultos ofensores sexuais também viveram experiências de violência, sendo esse aspecto já bastante elucidado (Blomet al., 2014; Cotter, Drake, \& Yung, 2016). Os últimos anos têm revelado uma preocupação de autores que pesquisam sobre o homem adulto ofensor sexual e seu próprio sofrimento em relação a vivências violentas em suas histórias de vida, retomando a importância da pesquisa qualitativa para a melhor compreensão das dinâmicas abusivas (Bowden, Glorney, \& Daniels, 2017; Geiger \& Fischer, 2017; Winder, 2017). Nesse sentido, Conceição, Penso, Costa, Setubal e Wolff (2018) vêm propondo o método psicodramático como mediador no trabalho prático de aprofundamento da compreensão do sofrimento desses sujeitos nas ações terapêuticas. Por exemplo, não abordar o tema do abuso sexual sofrido durante a infância pode se constituir em um impasse na progressão do processo terapêutico do homem adulto que ofendeu sexualmente (Bowden et al., 2017).

Ainda é importante indicar que Willis e Levenson (2016) apontam o erro que muitos programas realizam de oferecerem o mesmo modus operandi de atendimento ao homem ofensor sexual para os casos de mulher ofensora sexual. Assim, um fator muito importante que faz diferença mar-

(n)


cante para o atendimento da mulher ofensora sexual é a consideração das suas muitas vitimizações, e da maior agressividade contida nessas violências. Esse é o aspecto principal da contribuição do texto.

\section{MÉTODO}

Trata-se de recorte de uma pesquisa desenvolvida em uma parceria interinstitucional de pesquisa/consultoria entre um programa de atendimento psicossocial de uma secretaria de saúde de governo e uma universidade pública. $\mathrm{O}$ programa de atendimento a adultos que cometeram violência sexual contra crianças e adolescentes e tem seu espaço em hospital geral público teve início em 2013, já tendo sido atendidos 150 homens. Todos os atendimentos são realizados por encaminhamento pelo Sistema Judiciário e outros Serviços de Saúde (público e privado). No ano de 2016 começaram a chegar ao programa encaminhamentos do Ministério Público e da Vara da Infância para atendimento também de mulheres que cometeram ofensa sexual, o que desafiou a equipe a se instrumentalizar para obter conhecimento teórico e metodológico específico para a atenção à mulher ofensora sexual. Os encaminhamentos são realizados após cumprimento da pena em sistema fechado (no caso dos sujeitos do gênero masculino vindos da Vara de Execuções Penais), ou após recebimento de pena alternativa (no caso dos sujeitos do gênero masculino vindos da Vara de Execução de Medidas Alternativas). Com relação às mulheres ofensoras sexuais, até o momento os encaminhamentos foram realizados pelo Ministério Público e pela Vara da Infância e Juventude.

A opção pelo método recaiu sobre a Pesquisa Documental (Berg, 1998) em função de que os/as ofensores/ ofensoras sexuais não aceitam participar de atividades (como uma pesquisa) nas quais precisam se identificar como ofensores/as sexuais (Wolff, Oliveira, Marra, \& Costa, 2016). A depender dos contextos jurídico, psicossocial, clínico, e dos profissionais para quem estão informando, essas pessoas negam ou admitem o ato violento cometido. A principal fonte das informações foi o prontuário no qual está registrado tudo a respeito dos sujeitos.

As participantes foram cinco mulheres com idades entre 19 e 52 anos, encaminhadas pelo Sistema de Justiça e por serviços de saúde, sendo que ainda estão em atendimento psicossocial. Essa amostra significa 100\% da população atendida no primeiro semestre de 2018. O procedimento de acesso às mulheres teve o seguimento: primeiro houve estudo de caso por meio de discussão conjunta dos profissionais (psicólogos e assistentes sociais) que acompanham diretamente cada mulher, com outros profissionais da equipe (psicólogos, assistentes sociais e psiquiatra). Em seguida os prontuários foram consultados e retiradas as informações referentes às várias agressões sofridas por elas em seu curso de vida. A síntese dessas informações encontra-se na Tabela 1 , na seção Resultados.

A análise desses achados seguiu orientação de priorizar as vivências de violência nos aspectos físico, emocional, sexual, psicológico, negligência, trabalho infantil, abandono, vivência de rua (Cauffman, 2008; Grattagliano, Owens, Morton, Campobasso, Carabelle, \& Catanesi, 2012; Willis \& Levenson, 2016). Primeiramente as informações foram retiradas e posteriormente agrupadas para compreensão do processo de ocorrência das vivências apontadas. Buscou-se orga- 
nizar esse material contemplando-se as questões culturais e de ordem socioeconômicas como são valorizadas por Bowdenet al. (2017) e Geiger e Fischer (2017). O projeto foi submetido ao Comitê de Ética do Instituto de Ciências Humanas da Universidade de Brasília e recebeu parecer favorável datado de 19/02/2015.

\section{RESULTADOS}

Os resultados referentes às agressões impostas às vítimas estão descritos, de forma sucinta, na Tabela 1 . Logo em seguida são relatadas, com mais detalhes, as histórias de vitimizações precoces sofridas pelas mulheres que perpetraram as violências sexuais.

Tabela 1: Informações sobre a ofensora sexual como vítima

\begin{tabular}{|c|c|c|c|c|c|c|c|c|c|}
\hline \multirow[b]{2}{*}{ Participantes } & \multirow[b]{2}{*}{$\begin{array}{l}\text { Idade } \\
\text { atual }\end{array}$} & \multicolumn{8}{|c|}{ Idade Vitimizações } \\
\hline & & $\begin{array}{c}\text { Violência } \\
\text { sexual } \\
\text { intrafamiliar }\end{array}$ & $\begin{array}{c}\text { Violência } \\
\text { sexual } \\
\text { extrafamiliar }\end{array}$ & $\begin{array}{l}\text { Violência } \\
\text { física }\end{array}$ & $\begin{array}{l}\text { Violência } \\
\text { psicológica }\end{array}$ & Abandono & Negligência & $\begin{array}{c}\text { Trabalho } \\
\text { infantil }\end{array}$ & $\begin{array}{c}\text { Situação } \\
\text { de rua }\end{array}$ \\
\hline 1 & 52 & 17 a 19 & 11 e 14 & $\begin{array}{c}11,22 \mathrm{a} \\
27\end{array}$ & 22 a 27 & & & 11 & \\
\hline 2 & 41 & & 8,12 e 40 & & & & & & \\
\hline 3 & 45 & 25 a 41 & & $\begin{array}{c}\text { Infância } \\
25 \text { a } 41\end{array}$ & $\begin{array}{c}\text { Infância } \\
25 \text { a } 41\end{array}$ & & & 10 & \\
\hline 4 & 29 & & 9 e 13 & 13 e 16 & & & 15 & & 14 \\
\hline 5 & 19 & $\begin{array}{c}6, \\
\text { adolescência }\end{array}$ & & 17 & $\begin{array}{c}\text { Infância, } \\
17\end{array}$ & & & & \\
\hline
\end{tabular}

A participante 1, aos 11 anos, estava no parque brincando com uma menina da mesma idade, quando um senhor se aproximou e ofereceu-se para brincar com elas, e acabou por tocá-las nas partes íntimas. Tempos depois, após a morte do seu pai, ela e a irmã foram forçadas a realizarem todo o serviço doméstico, por cobrança da mãe. Quando as tarefas não eram cumpridas, a mãe as agredia fisicamente com correia de couro, batia em sua cabeça, e machucava com vassoura. Aos 14 anos: foi convidada por uma amiga de 19 anos para ir a uma festa. Ao chegar na festa, estavam apenas o namorado da amiga e mais um rapaz, que "tentou tocá-la". Como ela chorava muito, ele foi embora. Dos 17 aos 19 anos: conheceu seu primeiro namorado, sendo que não gostava que ele tocasse em seu corpo. Em seu aniver- sário de 19 anos, este namorado a estuprou e ela acabou por engravidar de seu primeiro filho. Dos 22 aos 37 anos: sofreu violência física e psicológica de um companheiro. Foi feita denúncia desta agressão física. Quando voltou para casa, após alta hospitalar, esse companheiro tentou pôr fogo na casa. Ele ainda foi acusado de ter cometido violência sexual com suas três filhas, entre 2005 e 2007, quando as meninas estavam com nove, oito e cinco anos. A avó materna das meninas registrou denúncia na delegacia. A participante 1 foi acusada de ter ciência das violências e de ter agredido as filhas para impedir a revelação da violência sexual por meio de ameaças, espancamentos e castigos, que ocorreram todas as vezes em que as meninas disseram que contariam o que acontecia. Ela chegou a atear fogo em uma parte do corpo de 
uma das meninas. Houve condenação a oito anos de prisão e perda do pátrio poder. Foi presa e permaneceu em regime fechado por mais de um ano.

A participante 2 e sua irmã gêmea "brincavam de médico", na vizinhança, com meninos que tinham entre oito e 14 anos. Um morador da mesma rua onde a família morava convidou as duas crianças para entrarem em sua casa, tendo ambas sofrido violência sexual com penetração. As crianças relataram à mãe que, validando o relato, pensou em registrar denúncia na delegacia, mas o autor da violência falou que seriam "palavra delas contra a dele". A participante 2 tem diagnóstico de retardo mental moderado, avaliado por psiquiatra de uma organização não governamental. Esta participante tem sido atendida fora do sistema público de saúde por uma psicóloga que elaborou um documento de encaminhamento ao programa no qual indica que há 11 anos a participante abusou de um menino filho de amigas da família, e que esta criança ainda tem contato com ela. No decorrer dos atendimentos, a participante 2 informou que cometeu violência sexual com um sobrinho que atualmente está com 14 anos de idade. Também relatou que, quando tinha 21 anos, cometeu violência sexual com uma criança pequena. A participante diz não entender que seus atos se constituem em violência, pois "não faz mal à criança”. Não há processo de responsabilização, uma vez que nunca houve denúncia. Ela participa de relacionamentos sexuais nos quais se submete, em virtude de sua vulnerabilidade, a determinadas práticas que posteriormente causam sofrimento.

A participante 3, durante a infância, presenciava violência física e psicológica do pai para com a mãe. À medida que cresceu, na tentativa de proteger a mãe, começou a enfrentar o pai e passou a sofrer violência física e psicológica do mesmo. Quando adulta, sofreu violência física e psicológica de seu próprio companheiro, por meio de empurrões, pontapés, tapas, murros e ameaça de morte com uso de arma. Após ter feito denúncia da violência doméstica, houve um acordo. Durante o relacionamento conjugal, a filha sofria violência sexual pelo companheiro da mãe, dos 5 aos 14 anos. A participante 3 relatou ter sido obrigada a estar junto nas violências sexuais e tinha o papel de preparar e convencer a filha a se submeter aos abusos sexuais. Em outros momentos, ciente de que os estupros ocorreriam, saía de casa para passear com o sobrinho. A violência sexual somente foi revelada quando a filha se tornou adulta.

A participante 4 , aos nove anos, sofreu violência sexual com penetração cometida por um vizinho da família. Posteriormente, em função de grandes conflitos com a mãe, esta tentou colocá-la em instituição de acolhimento, mas o pai não deixou. Desse modo, ela permaneceu em casa. Aos 13 anos, namorou um rapaz que dizia ter 19 anos, tendo fugido de casa para morar com ele, o qual acabou por agredi-la com murros. A escola denunciou porque ela estava machucada. Aos 14 anos foi morar na rua, e escondia-se do pai que queria levá-la para casa. Aos 15 anos, saiu da rua e foi morar na casa de uma colega do colégio. Conheceu seu atual marido com 19 anos, que cometeu violência física contra ela por várias vezes. A participante cometeu violência sexual contra suas filhas de seis e oito anos, na própria residência. A violência consistia em pedir às filhas que tocassem sua genitália (esse foi o relato da participante). O relato de uma filha vitimizada foi que a mãe acordava as duas filhas durante a noite, manipu- 
lava suas genitálias, alisava suas nádegas e pedia que as filhas a tocassem na genitália, ameaçando bater nelas se contassem ao pai. A situação ocorreu por várias vezes. As filhas dormiam no mesmo quarto do casal. Uma das filhas vitimizadas revelou a violência na escola, que acionou o conselho tutelar. Houve registro de ocorrência policial. Foi decretada medida protetiva de afastamento do lar da ofensora e de proibição de aproximação de contato (90 dias). As crianças foram encaminhadas para atendimento, e a vitimizadora também. Recentemente, o processo criminal foi arquivado.

A participante 5, durante sua infância e adolescência, presenciava as agressões físicas e psicológicas cometidas pelo pai contra a mãe, sendo que a mãe lhe perguntava o que fazer diante da situação. Aos seis anos sofreu violência sexual do primo nove anos mais velho, na adolescência sofreu assédio do namorado da mãe e, posteriormente, de um namorado. Foi encaminhada ao programa por ter relatado fantasias sexuais com crianças em um atendimento em outra instituição pública. A participante apresenta histórico de tentativas de suicídio e suspeita de transtorno de personalidade borderline (ainda em investigação). Em seu último relacionamento, relatou haver trocas de agressões físicas e verbais. Não há admissão, pela participante, de prática de ofensa sexual.

\section{DISCUSSÃO}

As "histórias de horror" (Grattagliano et al., 2012, p. 180) vividas por essas mulheres têm início muito precocemente, na infância, assim como indicam os autores sobre o tema (Blom et al., 2014; Cauffman, 2008; Comartin et al., 2018; Levenson et al., 2015;
Loinaz, 2016; Strickland, 2008; Willis \& Levenson, 2016). Essa violência se mostra contínua, permanente, se expressando em várias facetas: física, abandono, negligência, vivência de rua e, principalmente, a violência sexual. Ainda na infância dessas mulheres ocorrem mortes, separações e ruptura de vínculos afetivos que determinam grandes mudanças e desvinculações do ambiente e de pessoas. Pode-se observar também processos de empobrecimento material, de escolarização e de oportunidades de inserção social em função desses acontecimentos, assim como indicam os autores citados e os registros nos prontuários.

A compreensão das características socioambientais (condições de infraestrutura, saneamento, proximidade de criminalidade) e da presença da violência na comunidade vem recebendo atenção no sentido de que essas características são também fatores de risco e aumento da vitimização (Grossi, 2017; Willis \& Levenson, 2016). Além disso, há concordância de que a violência atinge mais agressivamente a mulher (ou a menina ou a adolescente), e deve ser estudada em separado em seus efeitos, em relação à violência que atinge $o$ homem (ou o menino ou o adolescente) (Lauritsen \& Carbone-Lopez, 2011). Lauritsen e Carbone-Lopez (2011) realizaram pesquisa para averiguar se os fatores pessoa, família e vizinhança diferem em relação ao gênero, com maior ou menor influência na vitimização. Concluiu-se que o gênero modera esses três fatores na vitimização pela violência (Lauritsen \& Carbone-Lopez, 2011; Pflugradt, Allen, \& Marshall, 2018). No que diz respeito à violência sexual, a menina permanece mais tempo em família, e isto aumenta as possibilidades de vitimização e revitimização. O que ainda ocorre em desvantagem com relação ao sexo femini- 
no é o fato de que as mulheres acabam por se associar com homens violentos, como foi descrito por todas as cinco participantes (Lauritsen \& Carbone-Lopez, 2011).

Dessa forma, a violência quase se perpetua por toda a vida, ocorrendo na adolescência, na fase de jovem adulta, na gestação, na conjugalidade (participantes 1,3 e 4). Nesse ponto há que se referenciar as questões de transgeracionalidade que se repetem na vivência e sofrimento pela violência, bem como na relação violenta com as filhas, como acontece com as participantes 1 e 3. A experiência de vitimização e/ou vitimização sexual ocorre em função de delegações não explícitas, mas apreendidas como forma e qualidade de estabelecimento de relações com outras pessoas. A delegação se manifesta como um mandado transmitido de geração a geração, e se efetiva em função da existência de uma lealdade invisível que permanece e "exige" que haja reprodução de uma forma de interagir (Boszormenyi-Nagy \& Spark, 1983).

Um aspecto que merece atenção é a forma como a ofensa sexual cometida por mulheres se manifesta. A participante 3 cometeu ofensa sexual contra a filha, em coautoria com o companheiro. Nesse caso, tem-se violência sexual materna que necessita ser compreendida de maneira distinta da violência sexual cometida por mulher. A violência sexual cometida por mulher pode ser realizada unicamente por ela, ou em parceria com um homem desconhecido ou com um companheiro habitual. As mulheres mais independentes cometem violência sozinhas (Loinaz, 2016). Por isso, o fato de cometerem violência sexual com um parceiro habitual (relação conjugal ou estável) indica uma possível dependência e submissão dessa mulher, trazendo para o centro da discussão uma dimensão de gênero presente (Cauffman, 2008; Gillespie, Williams, Elliot, Eldridge, Ashfield, \& Beech, 2015). Para Peter (2009), quando há a presença desse parceiro a mulher é mais jovem, ou mantém com ele um relacionamento submisso há muito tempo.

$\mathrm{Na}$ fase adulta, a mulher ofensora sexual reproduz o padrão de relação violenta que recebeu de seus cuidadores (Oliver \& Holmes, 2015), pois as meninas são mais suscetíveis para essa reprodução porque vivenciam os acontecimentos com mais sensibilidade quando pequenas. Os abusos sexuais das mulheres se dirigem mais às meninas e crianças conhecidas, e quando ocorrem com meninos, estes têm menor idade (Strickland, 2008). A pequena amostra desse texto encontra ressonância com essas informações. As violências sexuais cometidas contra meninos tendem a ficar encobertas por mais tempo, pois o menino é usualmente cuidado por uma mulher, então o abuso sexual fica sub-notificado, porque os atos abusivos são vistos como cuidados e não como abuso (Strickland, 2008). As crianças que ficam sob sua responsabilidade são escolhidas em função de poderem manter um contato mais próximo sem se envolverem com maior intensidade, em função da aprendizagem de um padrão de inadequação e isolamento social que leva à dificuldade de estabelecerem relações amorosas autênticas (Strickland, 2008).

Outro ponto importante e característico da violência sexual cometida por mulher é que a situação da violência pode permanecer por mais tempo, ou surgirem várias situações que facilitam a condição de abuso, porque as mulheres são vistas como cuidadoras (Kington, 2014). A trajetória da participante 2 ilustra essa questão. A presença do preconceito de que mulheres são 
sempre cuidadoras existe em relação à sociedade e em relação às próprias ofensoras, já que elas não reconhecem o abuso como violência e justificam que não podem ser vistas como agressoras, pois são as mães. Desse modo, as ofensoras se mantêm sem denúncia, responsabilização e, o mais importante: sem receberem qualquer tipo de ajuda (Gannon \& Alleyne, 2013; Grattagliano et al., 2012; Levenson et al., 2015; Willis \& Levenson, 2016). Os preconceitos de gênero influenciando negativamente a identificação da violência cometida por mulheres podem se mostrar impactantes no contexto jurídico e clínico (Pflugradt, Allen, \& Marshall, 2018; Weinsheimer, Woiwod, Coburn, Chong, \& Connolly, 2017).

Com relação à responsabilização, observa-se uma débil resposta da sociedade e da justiça. A participante 1 foi a que teve uma responsabilização mais definida: foi condenada a oito anos de prisão por cada vítima, perda do pátrio poder (artigos 214, atentado violento ao pudor, posteriormente revogado, juntamente com o artigo 224, alínea “a”, presunção de violência - menor de 14 anos, posteriormente revogado, e artigo 226, inc. III e art. 71 / Todos os crimes praticados em acordo com o art. $5^{\circ}$ - violência doméstica, da Lei n. 11.340/2006 (Lei Maria da Penha). Ela foi presa e permaneceu em regime fechado por um ano e seis meses, em regime semiaberto por um ano e, no momento, está em prisão domiciliar até 2019. Sobre a participante 2 não houve notificação, e a participante 3 não tem ainda conclusão sobre o processo criminal. O mesmo se seguiu com a participante 4 , que teve processo criminal arquivado, e a participante 5 não teve nenhuma notificação e nem denúncia. Punição e responsabilização são condições diferentes. Considera-se responsa- bilização como o processo de reconhecimento do dano causado à outra pessoa. Por esta razão, apesar de ter havido uma resposta punitiva advinda da justiça, o encaminhamento para atendimento é visto como o momento mais próximo a um possível processo de reconhecimento desse dano.

Kington (2014) é explícita em afirmar que a justiça criminal é leniente com a mulher que ofende sexualmente, em especial com a mãe que assim procede. Peter (2006) também aponta a presença de preconceito indicando que a criança sob a responsabilidade da mãe está sempre protegida, o que não é verdade sempre. Há uma verdadeira "cegueira" da sociedade em sequer duvidar dessa assertiva porque a sociedade descreve o homem abusador sexual como mau/monstro/diabo, e não há espaço para a desconfiança em relação à qualidade das ações da mulher. Com relação à mulher que abusa sexualmente, a sociedade não sabe como classificar ou onde colocar essa informação. A mulher ofensora sexual é vista como doida, pessoa ruim ou, até mesmo, doente mental, face à dificuldade de compreender que se trata de uma expressão de grave distúrbio emocional e psíquico e que esta ofensora necessita de atendimento especializado (Willis \& Levenson, 2016).

Sobre as vítimas, é importante reportar que, quando houve notificação ao sistema de saúde, por meio do preenchimento da Ficha de Notificação de Agravos (Ministério da Saúde, 2015), e posterior denúncia, houve também encaminhamento para atendimento psicológico, como foi o caso das três filhas da participante 1, e das duas filhas da participante 4. Autores como Cortoni et al. (2017), Blom et al. (2004), Goldhill (2013), Peter (2006), Willis e Levenson (2016) comprovaram em estudos qualitativos com 
as vítimas de abuso sexual cometido por mulheres que os danos emocionais provenientes dessas experiências são muito prejudiciais e tendem a se prolongar por muito tempo pois, para muitas dessas vítimas, não foi possível a interrupção da violência pela falta de crédito sobre a existência da mesma, ainda mais cometida por quem cuidava dessas vítimas. Goldhill (2013) ainda acrescenta que essas consequências são, atualmente, estudadas e descritas (não no Brasil) e, mesmo assim, os tribunais permanecem sendo pouco responsáveis com essa questão. A ausência de notificação sugere que as vítimas seguiram, ou ainda seguem, em situação de extrema vulnerabilidade.

Um aspecto sensível da história de violências sofridas por essas mulheres é quanto à situação de abandono em que se encontraram ao longo de suas vidas, seja abandono afetivo ou abandono do local de pertencimento. A participante 1 foi vítima de trabalho infantil, com a participante 2 houve uma tentativa da mãe de levá-la para uma instituição de acolhimento, sendo que depois foi morar na rua. É preciso que esses movimentos de desvinculações ou de rompimento de relações afetivas sejam considerados de maior importância, porque se constituem em um aspecto primordial dos problemas na afetividade da mulher ofensora sexual. Como meninas, sofreram maus-tratos e abandonos; como adultas, não conseguiram estabelecer identificação positiva com figuras femininas (em geral isso ocorre com a mãe) cuidadoras e cresceram com graves danos ao seu desenvolvimento afetivo emocional. Esses danos são agravados por condições sociais de gênero, colocando-as em posição inferiorizada ou dependentes de homens violentos (Willis \& Levenson, 2016).
E finalmente, ainda se deve apontar a grande quantidade de possíveis vítimas sem uma identificação adequada. A participante 2 informou que abusou de uma criança sem maiores informações. A participante 5 oferece informação não muito precisa sobre se abusou ou não de crianças, admitindo, até o momento, ter fantasias desta natureza. Apesar de essas mulheres permanecerem ainda em atendimento, constata-se uma situação conflitante, pois é preciso estabelecer vínculo de confiança com a ofensora, e ao mesmo tempo não se afastar de princípios éticos envolvidos nessa situação. $\mathrm{O}$ conflito diz respeito principalmente ao conhecimento, durante o processo de atendimento, por parte dos profissionais de que há crianças e/ou adolescentes em risco de serem abusadas sexualmente.

\section{CONSIDERAÇÕES FINAIS}

Neste texto foram problematizadas as violências sofridas por mulheres que cometeram ofensa sexual. Este ponto se constitui em um aspecto primordial de toda a intervenção psicossocial ou clínica com essa população. Os autores consultados neste trabalho concordam que essas mulheres necessitam ser atendidas em uma condição de acolhimento e estabelecimento de relação de confiança, sem julgamento ou crítica sobre sua conduta. A presença de ideias preconcebidas de que a mulher sempre cuida ou que a maternidade é imaculada pode toldar um olhar investigativo sobre o problema, seja por parte da sociedade ou dos profissionais.

O quadro traçado na Tabela 1 é bastante rico na apresentação das várias violências sofridas pela mulher que comete violência sexual, e de suas variadas formas. $\mathrm{O}$ risco de se invisibili- 
zar ou desqualificar as ofensas sexuais praticadas por mulheres se estende não só ao sistema de saúde, mas também ao sistema de justiça e todo o sistema de garantia de direitos de crianças e adolescentes (Lei n. 8069/1990). Observa-se que, ao se atender mulheres autoras de violência sexual, é preciso formação e estudo específicos, pois se corre o risco de vê-las mais como vítimas ou como vitimizadoras, dicotomizando a questão. A abordagem a essa mulher é complexa e específica, não podendo se negligenciar a influência do gênero em sua constituição psíquica emocional e social, bem como na resposta social apresentada a este problema.

\section{REFERÊNCIAS}

Blom, $H_{\text {s, }}$ Högberg, $\mathbf{V}_{\text {rg }}$ Olofsson, N., \& Danielsson, I. (2014). Strong Association Between Earlier Abuse and Revictimization in Youth. $\mathrm{BMCPu}$ blic Health, 14, 715.http://dx.doi. org/10.1186/1471-2458-14-715.

Boszormenyi-Nagy, I. \& Spark, G. M. (1983). Lealtades Invisibles. Buenos Aires: Amorrortu.

Bowden, L., Glorney, E., \& Daniels, M. (2017).Individual's experiences of sexual offending therapy in a forensic psychiatric setting. Journal of Sexual Aggression, 23(3), 278290. http://dx.doi.org/10.1080/135 52600.2017 .1343398

Budd, K. M. \& Bierie, D. M. (2018). Victims of sexual assault perpetrated by female youth: an exploratory study of gender differences. Journal of Sexual Aggression, 24(3), 274-293. https://doi.org/10.1080/1 3552600.2018 .1528793

Burgess-Proctor, A., Comartin, E. B., \& Kubiak, S. P. (2017). Comparing Female- and Male Perpetrated Child Sexual Abuse: A Mixed-
Methods Analysis. Journal of Child Sexual Abuse, 26(6), 657676. https://doi.org/10.1080/105 38712.2017.1336504

Cauffman, E. (2008). Understanding the Female Offender.The Future of Children, 18(2), 119-142. http:// dx.doi.org/10.1353/foc.0.0015

Comartin, E. B., Burgess-Proctor, A., Kubiak, S., \& Kernsmith, P (2018). Factors related to co-offending and coerced offending among female sex offenders: The role of childhood and adult trauma histories. Violence and victims, 33(1), 5374. https://doi.org/10.1891/08866708.VV-D-16-00073

Conceição, M. I. G., Penso, M. A., Costa, L. F., Setubal, C. B., \& Wolff, L. S._(2018).O Psicodrama na Intervenção Psicossocial com Adulto Autor de Violência Sexual. In L. F. Habigzang, P. I. C Gomide, \& G. M. da Rocha (Eds.), Psicologia Forense. Temas e Práticas (pp.79-110). Curitiba: Juruá.

Cortoni, Fr, Babchishin, Kr, \& Rat, C. (2017). The Proportion of Sexual Offenders Who are Female Is Higher than Thought. A Meta-Analysis. Criminal Justice and Behavior, 44(2), 145-162. https://doi. org/10.1177/0093854816658923

Cotter, J., Drake, R. J., \& Yung, A. R. (2016). Adulthood Revictimization: looking beyond childhood trauma. ActaPsychiatricaScandinavica, 134(4), 368.

Gannon, T. A. \& Alleyne, E. K. A. (2013). Female Sexual Abusers Cognition: A Systematic Review. Trauma, Violence \& Abuse, 14(1), 67-79. http://dx.doi. org/10.1177/1524838012462245

Geiger, B. \& Fischer, M. (2017).Incarcerated Sex Offenders in Rehabilitation Account for their Offending. Journal of Investigative Psychology 
and Offender Profiling, 14, 43-59. http://dx.doi.org/10.1002/jip.1460

Gillespie, S. M., Williams, R., Elliot, I. A., Eldridge, H. J. Ashfield, S., \& Beech, A. R. (2015). Characteristics of Female Who Sexually Offend: A Comparison of Solo and Co-offenders. Sexual abuse: A Journal of Research and Treatment, 27(3), 284-301. http://dx.doi. org/10.1177/1079063214556358

Goldhill, R. (2013). What Was She Thinking? Women Who Sexually Offend Against Children - Implications for Probation Practice.Probation Journal, 60(4), 415-424. http://dx.doi. org/10.1177/024550513502248

Grattagliano, I., Owens, J. N. Morton, R. J., Campobasso, C. Pr, Carabelle, F., \& Catanesi, R. (2012).Female sexual offenders: Five Italian case studies. Aggression and Violent Behavior, 17, 180-187. http://dx.doi. org/10.1016/j.avb.2012.01.001

Grossil, L. M. (2017). Sexual Offenders, violent offenders, and community reentry: challenges and treatment considerations. Aggression and Violent Behavior, 34, 59-67. http://dx.doi.org/10.1016/j. avb.2017.04.005

Kington, A. (2014). The Sex Offender no One Suspects: The Treatment of Female Teachers Who Sexually Exploit Male Student Reflects Legal and Cultural Double Standards. MacLean's, 12, 43-44. http://www2. macleans.ca /

Lauritsen, J. L. \& Carbone-Lopez, K. (2011). Gender Differences in Risk Factors for Violent Victimization: A Examination of Individual-, Family-, and Community level predictors. Journal of Research in Crime and Delinquency, 48(4), 538-565.https://doi. org/10.1177/0022427810395356
Lei n. 8.069, de 13 de julho de 1990. (1990). Dispõe sobre Estatuto da Criança e do Adolescente e dá outras providências. http://www6. senado.gov.br/legislacao/ListaPublicacoes.action? $\mathrm{id}=102414$

Lei n. 11.340, de 7 de agosto de 2006. (2006).Cria mecanismos para coibir a violência doméstica e familiar contra a mulher, e dá outras providências. http://www.planalto.gov.br/ccivil_03/_ato20042006/2006/lei/111340.htm

Levenson, J. S., Willis, G. M., \& Prescott, D. S. (2015).Adverse Childhood Experiences in the Lives of Female Sex Offenders. Sexual Abuse: A Journal of research and Treatment, 27(3), 258-283. https://doi. org/10.1177/1079063214544332.

Loinaz, I. (2016). Cuando "el" delincuente es "ella": intervención con mujeres violentas. Anuario de Psicologia Jurídica, 26, 41-50. https:// doi.org/10.1016/j.apj.2016.04.006

Ministério da Saúde. (2015). SINAN. Sistema de Informação de Agravos de Notificação. Ficha de Notificação Individual. http://www.saude. pr.gov.br/arquivos/File/Ficha_ Viol_5_1_Final_15_06_15.pdf

Nicoletti, M., Giacomozzi, A. I., \& Cabral, M. F. (2017). Análise de dois estudos de casos sobre abuso sexual cometido por mães. Revista de Psicologia, 35(2), 423452. https://doi.org/10.18800/ psico.201702.002

Oliver, B. E. \& Holmes, L. (2015). Female Juvenile Sexual Offenders: Understanding Who They Are and Possible Steps That May Prevent Some Girls From Offending. Journal of Child Sexual Abuse, 24, 698-715. https://doi.org/10.1080/ 1053712.2015.1058875

Peter, T: (2006). Mad, Bad, or Victim? Making Sense of Mother-Daughter 
Sexual Abuse. Feminist Criminology, 1(4), 283-302. https://doi. org/10.1177/1557085106292779

Peter, T. (2009). Exploring Taboos. Comparing Male-and FemalePerpetrated Child Sexual Abuse. Journal of Interpersonal Violence, 24(7), 1118-1128. https://doi. org/10.1177/0886260508322194

Pflugradt, D. M., Allen, B. P., \& Marshall, W. L. (2018).A gendered strength-based treatment model for female sexual offenders. $A g$ gression and Violent Behavior, 40, 12-18. https://doi.org/10.1016/j. avb.2018.02.012

Strickland, S. M. (2008). Female Sex Offenders.Exploring Issues of Personality, Trauma, and Cognitive Distortions. Journal of Interpersonal Violence, 23(4), 474-489. https://doi. org/10.1177/0886260507312944

Weinsheimer, C. C., Woiwod, D. M., Coburn, P. In, Chong, K., \& Connolly, D. A. (2017). The unusual suspects: Fe- male versus male accused in child sexual abuse cases. Child Abuse \& Neglect, 72, 446-455. https://doi. org/10.1016/j.chiabu.2017.09.003

Willis, G. M. \& Levenson, J. S. (2016). The Relationship Between Childhood Adversity and Adult Psychosocial Outcomes in Females who Have Sexually Offended: Implications for Treatment. Journal of Sexual Aggression, 22(3), 355-367. https://doi.org/10.1080/13552600. 2015.1131341

Winder, B. (2017).Interviewing convicted sexual offenders (and the merits of qualitative research). Nottinghan, UK: Trent University. http://irep.ntu.ac.uk/id/ eprint/32514/1/9967_Winder.pdf Wolff, L., Oliveira, E. S. Marra, M. M., \& Costa, L. F. (2016). O Recurso Psicodramático na Intervenção com o Adulto Autor de Ofensa Sexual. Revista Brasileira de Psicodrama, 24(2), 58-68. https://doi. org/10.15329/2318-0498.20160020
Cassia de Freitas Teixeira Passarela

Lucy Mary Cavalcanti Stroher Liana Fortunato Costa 
CASSIA DE FREITAS TEIXEIRA

PASSARELA

(https://orcid.org/0000-0001-5662-5024) Assistente social, Programa de Pesquisa, Atenção e Vigilância à Violência. Secretaria de Estado de Saúde do Distrito Federal. Programa de Pesquisa, Atenção e Vigilância à Violência PAV Alecrim - Secretaria de Estado de Saúde do Distrito Federal (SES-GDF).

E-mail: pav.alecrim@gmail.com

\section{LUCY MARY CAVALCANTI STROHER}

(https://orcid.org/0000-0002-4525-9281) Assistente social, Programa de Pesquisa, Atenção e Vigilância à Violência. Secretaria de Estado de Saúde do Distrito Federal. Programa de Pesquisa, Atenção e Vigilância à Violência PAV Alecrim - Secretaria de Estado de Saúde do Distrito Federal (SES-GDF). E-mail: lustroher@gmail.com

\section{LIANA FORTUNATO COSTA}

(http://orcid.org/0000-0002-7473-1362) Psicóloga, Programa de Pós-Graduação em Psicologia Clínica e Cultura da Universidade de Brasília (PPGPSICC-IP-UnB).

E-mail: lianaf@terra.com.br 